\title{
A FAMÍLIA E A ESCOLA: \\ Instituições Essenciais no Desenvolvimento da Educação Infantil e a Socialização
}

\section{Resumo}

Ana Cláudia Santana de Jesus ${ }^{1}$ Simone Ferreira de Jesus dos Santos ${ }^{2}$

Este artigo tem o objetivo de pesquisar a influência das instituições escolar e familiar na formação do indivíduo e sua parceria na promoção do cidadão. Nele serão abordadas as contribuições inerentes à família e à escola que são grandes instituições com seus valores, posturas e ponderações para com o indivíduo em formação respaldando-o por descobertas e reafirmações diante das diversidades culturais permeados por caminhos de reflexões para um bom desenvolvimento intelectual e social. A metodologia empregada nesta pesquisa foi a bibliográfica recorrendo a livros, textos e artigos de distintos autores que abordam sobre a temática. Conclui-se que uma equilibrada educação no seio da família, vinculada a à participação profícua com a instituição escolar, uma harmônica parceria e regada de valores: Possibilita uma estrutura sólida para um indivíduo, tornando-o capaz de enfrentar as adversidades e as possibilidades de um amadurecimento social, de seu autoconhecimento, limitações e possibilidades.

Palavras-Chave: Família. Escola. Educação Infantil. Socialização

\section{Abstract}

This article aims to research the influence of school and family institutions on the formation of the individual and their partnership in promoting the citizen. It will address the contributions inherent to the family and the school, which are great institutions with their values, attitudes and considerations towards the individual in training, supporting him / her with discoveries and reaffirmations in the face of cultural diversities permeated by paths of reflection for good intellectual development and Social. The methodology used in this research was the bibliographic one using books, texts and articles of different authors that approach on the subject. It is concluded that a balanced education within the family, linked to fruitful participation with the school institution, a harmonious partnership and full of values: It enables a solid structure for an individual, making him capable of facing the adversities and the possibilities of a social maturity, self-knowledge, limitations and possibilities.

Keywords: Family. School. Child education. Socialization

\section{Introdução}

A educação é um caminho na vida de qualquer indivíduo, onde ele vai colocar em paralelo suas interpretações e suas aquisições no processo de aprendizagem, percurso contínuo que precisa ser adaptado as realidade em que se encontra qualificada a educação e os caminhos ao qual vem traçando provenientes de conflitos escolar, familiar e social. Surgiram vários questionamentos inerentes ao panorama que vem se debruçando a escola, sendo cada vez mais desvalorizada. $A$

\footnotetext{
${ }^{1}$ Mestra em Ciências da Educação pela FICS. Especialista em Fundamentos do Ensino da Arte. Licenciatura em Educação Artística com Habilitação em Artes Plásticas (Universidade Católica de Salvador). Licenciatura em Letras Vernáculas (Universidade Federal da Paraíba) Coordenadora Pedagógica e Professora concursada no Município de Santo Amaro da Purificação-Bahia. Professora concursada no Município de Camaçari-Bahia. Email: calsantana26@hotmail.com

2 Mestra em Ciências da Educação pela Fics.Licenciada em Letras - Português/Espanhol e Respectivas Literaturas pela UNITINS.Graduanda em Pedagogia pela UNEF.Docente em São Sebastião do Passé- Ba - Escola Sonho de Criança.Email: simoneferreira12098az@gmail.com
} 
qual traz um estigma de seletiva. Onde a priori era voltada para as classes sociais providas de posses ou a necessidade política.

A escola tem um grande papel básico de socializar em seu processo formal; Contribuir com seus valores, normas estabelecidas e um programa estruturado. Enquanto que a educação informal vem a ser tudo o que pela criança é apresentado em sua relação com o meio ao qual faz parte, contribuindo para o seu desenvolvimento enquanto aluno e cidadão.

Atuando nesse espaço, a criança vai desvencilhar suas capacidades na perspectiva de construção da cidadania, tendo como alicerce a valorização da sua cultura diante da diversidade social. Para o pleno desenvolvimento do aluno é preciso potencializar a autoestima, a afetividade, a sua curiosidade, o lúdico e a individualidade de cada um, onde elas trazem de casa tudo o que por ele foi fixado, vivido e compartilhado, esse imenso mundo da aprendizagem que é um processo contínuo.

Nessa perspectiva, indaga-se o positivo no labor da escola e da família na formação do cidadão como ser único, transformador e formador de ideias. Com certeza, as duas instituições com grandes e importantes valores que contribuem para a formação de um indivíduo, no caso, o aluno, são aprendizagens que se complementam; Onde a negação de uma influência no desenvolvimento da criança.

O professor é o profissional que pode gerir o processo do saber com prudência sem esquecer que os valores, sejam trabalhados ainda na primeira infância, por fazermos parte de uma sociedade inserida em um mundo globalizado e cercado por constantes mudanças. Muitos conflitos que hoje permeiam nossa sociedade se devem à negação dos valores morais, os quais consistem num conjunto de qualidades que estão presentes na nossa vida nos caracterizando como seres humanos e nos diferenciando das demais espécies.

As transformações são constantes até na área familiar, a qual vem adquirindo um novo formato entre seus membros, essas mudanças vivenciadas no contexto social trazem o pensar sobre essa transformação na vida do aluno e/ou filho, os quais precisam desta base para o seu pleno desenvolvimento em todas as suas nuances, pois "a família como toda instituição social, apesar dos conflitos é a única, 
que engloba o indivíduo em toda a sua história de vida pessoal" (PRADO, 1981, p.9).

Nosso papel enquanto professor está em estabelecermos os espaços e utilizarmos dos materiais que dispormos potencializando 0 processo de aprendizagem. Isso implica que o professor deverá ser um facilitador, compreendendo que a criança já traz suas pré-construções, às quais devem ser lapidadas.

\section{Família, Escola e Valores na formação do cidadão.}

Falar em educação nos faz refletir que ela sintetiza plenitude, alicerçada entre o diálogo entre instituições primordiais como a família e a escola. Os seres humanos ao longo da vida passam por processos de ensino e se humanizam, para ser amparados na sociedade a educação precisa de proposta pedagógica voltadas aos valores humanos.

Para o pleno desenvolvimento do aluno é preciso potencializar a autoestima, a afetividade, a sua curiosidade, o lúdico e a individualidade de cada um, onde elas trazem de casa tudo o que por ele foi fixado, vivido e compartilhado nesse imenso mundo da aprendizagem que é um processo contínuo, uma vez que:

\footnotetext{
Educação não é só ensinar, instruir, treinar, domesticar, é, sobretudo formar a autonomia do sujeito histórico competente, uma vez que, educando não é objetivo de ensinar, mas sim sujeito do processo de trabalho, trabalho este entre individualidade e solidariedade (DEMO.1996, p.16).
}

A educação é uma ação paralela entre indivíduo e a sociedade, caminho de associação e interpretação de sua importância nesse processo. Quando se pensa na formação de um indivíduo não tem como não cogitar sobre educação, mecanismo com um olhar amplo capaz de integrar indivíduo e sociedade.

Sem dúvida, para a escola, o processo de ensino-aprendizagem é uma preocupação singular, pois a escola é também um lugar onde a criança aprende para ser apresentada e educada para a vida em sociedade. À prática escolar precisa está amparada aos conteúdos de maneira a favorecer o olhar do aluno no seu dia a dia. Diante da realidade das transformações ocorridas no espaço contemporâneo, a aquisição da aprendizagem vem ganhando autonomia, levando o indivíduo a descobertas e reflexões em harmonia com as diversas culturas, novas formações de 
família, tecnologias sem perder o respeito, às quais darão um novo sentido as suas relações em sociedade.

A aprendizagem significativa é capaz de ampliar horizontes, favorecer a autocrítica do aluno, práticas que deverão levar o professor a pensar em cada aluno como único e que não somente o aluno seja responsável pelo próprio sucesso, pois é sabido que não existe uma única causa para as dificuldades de aprendizagem. 0 professor é o profissional que pode conduzir o processo do saber com prudência, pois:

\footnotetext{
Ao novo educador compete refazer a educação, reinventá-la, criar as condições objetivas para que uma democracia seja possível, criar uma alternativa pedagógica que favoreça o aparecimento de um novo tipo de pessoas, solidárias, preocupadas em superar 0 individualismo (GADOTTI, 1985, p.36).
}

Nosso papel enquanto professor, como é colocado por Gadotti, está em criarmos as possibilidades de aprendizagem utilizando de matérias que dispormos. Isso implica que o professor deverá ser um facilitador, compreendendo que a criança já traz suas pré-construções, às quais devem ser lapidadas e pensarmos em que tipo de cidadão estão sendo colocado no mundo em que vivemos e que muitos dos nossos farão parte.

$\mathrm{Na}$ busca para compreender a atual realidade em que se encontra qualificada a educação e os caminhos ao qual vem traçando, provenientes de conflitos escolar, familiar e social. Surgiram vários questionamentos inerentes ao panorama que vem se debruçando a escola, sendo cada vez mais desvalorizada. A qual traz um estigma de seletiva. Onde a priori era voltada para as classes sociais providas de posses ou a necessidade política.

A escola tem um grande papel básico de socializar em seu processo formal, contribuir com seus valores, normas estabelecidas e um programa estruturado. Enquanto que a educação informal vem a ser tudo o que pela .criança é apresentado em sua relação com o meio ao qual faz parte, contribuindo para o seu desenvolvimento enquanto aluno e cidadão. Atuando nesse espaço, a criança vai desvencilhar suas capacidades na perspectiva de construção da cidadania, tendo como alicerce a valorização da sua cultura diante da diversidade social. 
O indivíduo, para estar preparado para enfrentar a adversidade do tempo, precisa estar alicerçado de um caráter pessoal e profissional embasados em valores, pois é através deles que o indivíduo se conhece e sabe os seus limites e o respeito para com o outro. A sociedade vem passando por transformações o que faz eclodir o pensar da educação e de sua perfeita sintonia entre a família e a escola.

Tais instituições em suas divergências no papel que cada uma deve desempenhar ao ser que será inserido na sociedade é imprescindível encontrar caminhos que cooperem no desenvolvimento do aluno em suas dimensões: cognitiva, afetiva, social, ou seja, em sua formação cidadã, onde:

O envolvimento dos pais na educação das crianças tem uma justificativa pedagógica e moral, bem como legal. Quando os pais iniciam uma parceria com a escola, o trabalho com as crianças pode ir além da sala de aula, e aprendizagem na escola e em casa passam se complementam mutuamente (SPODERK; SARACHO, 1998, p.1677).

É nesse contexto que ambas as instituições potencialize os mesmos pensar e direcionamento visando o cidadão que almejamos para nossa sociedade e pelo qual somos responsáveis. A relação da escola e da família traz o refletir a sua importância para a educação e o desenvolvimento humano; ao nascer, a criança é inserida na sociedade com influências das famílias e acaba incorporando a cultura que a cerca, elencando bases de comportamentos nos valores morais, crenças, religião e ideias.

É imprescindível que a escola favoreça oportunidades para a família, para que se sintam acolhidas e amparada na participação efetiva na vida escolar do aluno regado de afeto, atenção e personalidade das mesmas, evidenciando seus papéis e ressaltando a importância na vida da criança, pois:

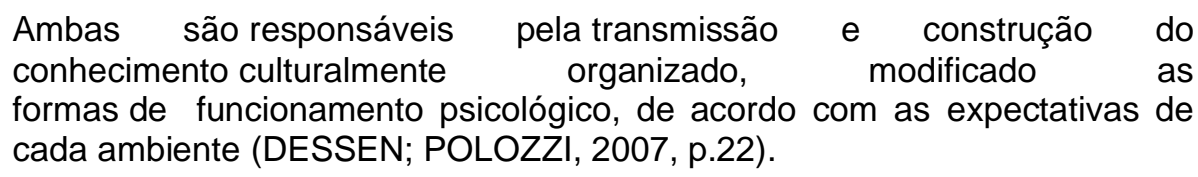

Nessa perspectiva, indaga-se o positivo no labor da escola e da família na formação do cidadão como ser único, transformador e formador de ideias. Com certeza, as duas instituições com grandes e importantes valores que contribuem para a formação de um indivíduo, no caso, o aluno, são aprendizagens que se complementam; Onde a falta de uma prejudica o desenvolvimento da criança. 
Pesquisas feitas descrevem a respeito da dificuldade de aprendizagem dos alunos, ocorram provenientes pela falta de uma boa base familiar, participação dos pais na vida dos filhos em seus diversos aspectos, distúrbios emocionais, psicológicos e de que os pais estão deixando a cargo dos professores toda a responsabilidade, que envolva a educação dos filhos.

Diante de tudo que nos é apresentado sobre a educação e a parceria entre família e escola, não cabe mais os pais só irem a instituição nos dias de reunião entre pais e mestres. É preciso criar momentos de atividade entre pais e filhos na instituição mesmo que seja uma vez em cada semestre, regadas por atividades para casa, onde seja necessária a participação dos pais em produção de texto, produção de artes, entrevista, projetos que envolva a família e agora com a utilização das tecnologias, outro ponto é utilizarmos a produção de vídeos em família.

Outro ponto chave é a afetividade, que precisa ser trabalhada tanto entre professores e alunos, como família / alunos e família e escola. É preciso também analisar as implicações das vivências dos valores humanos, na formação cidadã contemporânea proveniente da família e da escola, porque esses valores estão se perdendo e desencadeando um tempo de incerteza sentimental, social e profissional, salientando o individualismo exacerbado. Planejar um projeto que envolva a família pode ser um bom caminho.

Os valores humanos do mundo social, onde a escola está inserida, auxiliam na definição desse mundo e servem de modelos para suas atitudes e comportamentos. Caminhos para sua personalidade, seu desenvolvimento pessoal e intelectual, refletindo, consequentemente, no perfil de cidadão que virá a ser. A formação em valores humanos se torna um trabalho fundamental para a escola, uma vez que ela pode desenvolver em seus alunos, a capacidade de análise e reflexão crítica, pois:

A cidadania expressa um conjunto de direitos que dá à pessoa a possibilidade de participar ativamente da vida e do governo de seu povo. Quem não tem cidadania está marginalizado ou excluído da vida social e da tomada de decisões, ficando numa posição de inferioridade dentro do grupo social (DALLARI, 1998, p.14).

Imbuídos com este pensamento, a cidadania esteve e está em permanente construção. Sendo assim, não pode ser abandonada nem tão pouco colocada a cargo de apenas uma esfera social. É fundamental que tanto os pais como a escola 
assumam o papel de preparar cidadãos conscientes de seus direitos e deveres, pois "o cidadão que a sociedade tanto deseja, que tanto espera, começa a ser formado logo nos primeiros dias de vida, e continua sendo formado por toda a vida" (Ibid., p.15). Isso nos leva a reconhecer que o ser humano passa por constantes transformações durante sua vida, as quais influenciarão em sua comunicação e ação na sociedade da qual faz parte.

\begin{abstract}
A escola tem sido historicamente a instituição escolhida pelo Estado e pela família como melhor lugar para o ensino e aprendizagem dos valores, de modo a cumprir finalidade do pleno desenvolvimento da educação, seu pleno preparo para o exercício da cidadania e sua qualificação para o mundo do trabalho (ALBALA-BETRAND, 1999, p.22).
\end{abstract}

É importante que os valores sejam trabalhados ainda na primeira infância, por fazermos parte de uma sociedade inserida em um mundo globalizado e cercado por constantes mudanças. Muitos conflitos que hoje permeiam nossa sociedade se devem à negação dos valores morais, os quais consistem num conjunto de qualidades que estão presentes na nossa vida nos moldando como seres humanos e nos diferenciando das demais espécies.

Às As transformações são constantes até na área familiar, a qual vem adquirindo um novo formato entre seus membros. À priori, tinha-se como família 'ideal' um pai, a mãe e os filhos, o que nos remete à Bíblia sobre família, e "por isso deixará o homem o pai e a mãe e se unirá à sua mulher e se tornarão uma só carne" (Gen. 2,24)

Essas mudanças vivenciadas no contexto social trazem o pensar sobre essa transformação na vida do aluno e/ou filho, os quais precisam desta base para o seu pleno desenvolvimento em todas as suas nuances, pois "a família como toda instituição social, apesar dos conflitos é a única, que engloba o indivíduo em toda a sua história de vida pessoal" (PRADO, 1981, p.9). Essas transformações vivenciadas no contexto social e econômico trazem o pensar dessas relações na família e/ou até mesmo o desaparecimento da família tradicional.

$\mathrm{Na}$ família, desencadeou a falta do alicerce dos pais como primeiros formadores, deixando os seus filhos desestruturados, queixa por parte dos professores que acabam também sendo responsáveis por ajudar nessa educação: quando se fala na formação do cidadão, não cabe mais estabelecer limites e sim 
procurar estratégias para juntos, buscarem e solucionarem caminhos favoráveis para a formação em questão. Essas ramificações recaem sobre as escolas, pois:

Sabemos que a família e a escola são contextos de desenvolvimento e
aprendizagem e apenas essa constatação deveria bastar e ser suficiente
para justificar a necessidade que a escola e família trabalhassem
cooperativamente (CAETANO, 2014, p.22).

Diante das mudanças provenientes das diversas maneiras de pensar e agir, a sociedade trouxe e passa por construção e reconstrução na família, evidenciando a necessidade de uma nova forma de aprendizagem que considere as variantes para a formação do cidadão.

Diversos são os desafios relacionados com o papel e responsabilidade que cada instituição possui na formação integral da criança. Mudanças essas que vêm abalando o papel da escola, da família e da sociedade. Proveniente dessa realidade é necessário ter um novo olhar para a educação familiar e escolar, as quais vêm denunciar os tipos de cidadão que estão sendo inseridos na sociedade.

Negar a realidade é ficar de fora de que as mudanças na família, além de afetar a sociedade, afeta também a educação dos filhos. Realidade que ainda não se sabe como colocar, respeitando e acolhendo-a. É notório que as instituições sociais, passam por mudanças as quais estão redefinindo suas estruturas, seu significado e o seu papel na sociedade.

A escola é referendada como uma parte da família e, nessa atitude de formação de um cidadão crítico, é preciso trabalhar a convivência, que deve ser organizada de modo que o conceito como justiça, respeito e solidariedade seja compreendido, fazendo com que o aluno perceba que há coerência entre esses valores e o que ele espera da vida. Mediante tal abordagem faz-se necessário destacar que:

De modo real a divulgação de valores positivos com relação ao saber e ao estudo junto aos pais, para que estes trabalhem esses valores com seus filhos em casa, depende de uma comunicação muito eficiente entre escola e pais (PARO 2000, p.60).

Preocupações que podemos ver entre Paro, salientando que é na família onde se afirma o cuidado especial e produtivo pela vida, e são direcionados para a vivência macro social, acionando o essencial equilíbrio da família entre membros, 
reafirmando a necessária participação de todos e que a falta do mesmo afeta os outros.

A criança tem a sua formação desenvolvida em dois contextos, sendo a educação familiar e a escolar, parceria que se traduz em almejar e alcançar objetivos que se complementam. O objetivo é "transformar nossos filhos em homens de bem, em cidadãos, pessoas maravilhosas, homens íntegros, saudáveis fisicamente, intelectual e psiquicamente, de quem todos nos orgulharemos no futuro" (ZAGURY, 2008, p.213).

Diversos são os desafios relacionados com o papel e responsabilidade que cada instituição possui na formação integral da criança. O pensamento de outrora em que à família tem a responsabilidade de ensinar aos filhos valores morais assumidos diante da sociedade, e à escola a responsabilidade de ensinar os conhecimentos ditos científicos.

Esse pensamento, para os dias atuais, não é concebível, pois as mudanças ocorreram aceleradamente e o pensamento para uma ação coesa ao momento de desenvolvimento, não foram bem estruturados para as necessidades da sociedade.

Uma equilibrada educação no seio da família, vinculada a à participação profícua com a instituição escolar, regada de valores: Possibilita uma estrutura sólida capaz de enfrentar as adversidades $e$ as possibilidades de um amadurecimento social.

Um bom começo de uma grande mudança no relacionamento entre família e a escola, esteja baseada em diálogo e acolhimento o qual nem sempre será produtivo, pois cada família e cada escola vive realidade diferentes sociedade.

\section{Considerações Finais}

O processo de educação se processa de modo contínuo e denota-se plenitude, quando vem alicerçado pelo diálogo entre instituições primordiais como a família e a escola. Para o pleno desenvolvimento do aluno é imprescindível potencializar a autoestima, a sua curiosidade, o lúdico e a individualidade de cada um.

A escola é um espaço de socialização, nesta perspectiva a aprendizagem significativa precisa ser amparada por atividades tendo como elo o indivíduo e a sociedade, ou seja, caminho que leve a criança a vivenciar no seu dia a dia seus 
conteúdos programáticos. A sociedade vem passando por transformações o que faz eclodir o questionamento sobre educação e o tipo de cidadão que estamos colocando na sociedade.

Imbuídos diante deste pensar está a perfeita sintonia entre as instituições que é a família e a escola. Tais instituições precisam potencializar o mesmo pensar e direcionamento, visando o cidadão que almejamos. É imprescindível que a escola favoreça oportunidades para a família, para que se sintam acolhidas e amparadas na participação efetiva da vida escolar regada de afeto, atenção e personalidade das mesmas, evidenciando seus papeis e ressaltando a importância na vida da criança em seu processo de aprendizagem.

É preciso criar momentos de atividades entre pais e filhos na instituição, mesmo que seja uma vez em cada semestre, regados de atividades para casa, onde seja necessário a participação dos pais na produção de textos, entrevistas, projetos que envolva a família. A família é uma instituição que vem passando por transformações em sua estrutura, que pode também ser um gatilho positivo ou negativo para o aluno influenciando no seu processo de aprendizagem, quando não bem vivenciado o ser família, sua harmonia, respeito e o afeto entre os membros.

Imbuídos com este pensamento, revermos o cidadão que queremos e voltarmos a pensar na cidadania pautada nos valores que a família e a escola possuem e que estão se perdendo, onde a falta de uma das instituições afetam na aprendizagem da criança e na formação do cidadão conscientes de seus direitos e deveres.

\section{Referências}

ALBALA-BETRAND, L; MARTINS, M. S. Cidadania e educação: rumo a uma prática significativa. Campinas, Edu, 1999.

CAETANO, L. M. Escola e família: o que cabe a cada uma presente. Rio de Janeiro: Revista de Educação, 2014.

DALLARI, D. A. Direitos Humanos e Cidadania. São Paulo: Moderna, 1998.

DEMO, P, Educar pela pesquisa. Campinas. São Paulo: Editora Autores Associados,1996.

DESSEN, M. A; POLONIA, A. C. A família e a escola como contextos de desenvolvimento humano. Ribeirão Preto: Paideia, 2007. 
GADOTTI, M. Escola vivida. Escola projetada. 2. Ed. Campinas-São Paulo: Papires, 1985

PARO V.R.H. Qualidade do Ensino: A contribuição dos pais. São Paulo: Xamã. 2000.

PRADO, D. O que é família. 1 ed. São Paulo: Brasiliense,1981.

SPODEK, B; SARACHO, O. N. Ensinando crianças de $\mathbf{3}$ a 8 anos. Porto Alegre: Artmed, 1998.

ZAGURY, T. Escola sem conflitos: Parceria com os pais. Rio de Janeiro: Record.2008. 